\title{
Final Project Report
}

CRADA No.: $\quad$ BNL-C-94-07

Project Title: $\quad$ Peptide Based Radiopharmaceuticals: Specific Construct Approach

BNL P.I.

Industrial P.I.
Prantika Som, DVM, ScM.

Buck A Rhodes, Ph.D.

Shubh S. Sharma, Ph.D.

Palatin Technologies Inc., formerly RhoMed, Inc.

Albuquerque, NM

\section{Abstract:}

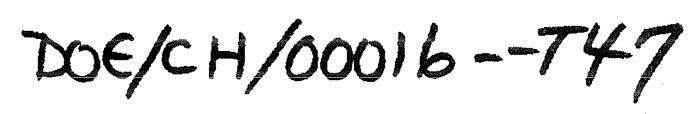

The objective of this project was to develop receptor based peptides for diagnostic imaging and therapy. A series of peptides related to cell adhesion molecules (CAM) and immune regulation were designed for radiolabeling with ${ }^{99 \mathrm{~m}} \mathrm{Tc}$ and evaluated in animal models as potential diagnostic ima,ng agents for various disease conditions such as thrombus (clot), acute kidney failure, and infection/inflammation imaging.

The peptides for this project were designed by the industrial partner, Palatin Technologies, (formerly Rhomed, Inc.) using various peptide design approaches including a newly developed rational computer assisted drug design (CADD) approach termed MIDAS (Metal ion Induced Distinctive Array of Structures). In this approach, the biological function domain and the ${ }^{99 \mathrm{~m}} \mathrm{Tc}$ complexing domain are fused together so that structurally these domains are indistinguishable. This approach allows construction of conformationally rigid metallo-peptide molecules (similar to cyclic peptides) that are metabolically stable in-vivo. All the newly designed peptides were screened in various in vitro receptor binding and functional assays to identify a lead compound. The lead compounds were formulated in a one-step ${ }^{99 \mathrm{~m}} \mathrm{Tc}$ labeling kit form which were studied by BNL for detailed in-vivo imaging using various animals models of human disease. Two main peptides using MIDAS approach evolved and were investigated: RGD peptide for acute renal failure and an immunomodulatory peptide derived from tuftsin (RMT-1) for infection/inflammation imaging.

Various RGD based metallopeptides were designed, synthesized and assayed for their efficacy in inhibiting ADP-induced human platelet aggregation. Most of these peptides displayed biological activity in the $1-100 \mu \mathrm{M}$ range. Based on previous work by others, RGD-I and RGD-II were evaluated in animal models of acute renal failure. These earlier studies showed that after acute ischemic injui $y$ the renal cortex displays RGD receptor with higher density. The results have indicated good diagnostic potential for their use in this clinical situation, as an imaging agent to diagnose ischemic renal injury and differentiate from other causes.

Very promising results were obtained with newly developed tufsin related metallopeptides. A number of these peptides displa ed high potency ( $\mathrm{nM}$ range) in imaging infection. Antagonists were successfully used to image experimentally induced abscesses in rodents. One of the agonists, termed ${ }^{99 \mathrm{~m}} \mathrm{Tc}-\mathrm{RMT}-1$, was evaluated in rabbits and dogs for its applicability as infection/inflammation imaging agent. Both in dog and rabbit infection/inflammation models ${ }^{99 m}$ Tc-RMT-1 m mld be used for rapid scintigraphic diagnosis. A very high and rapid uptake was observed in both soft tissue and bone infection providing a good target to background contrast. The agent also allowed distinction between bone fracture and osteomyelitis. All these results warrant human clinical trials with ${ }^{99 m}$ Tc-RMT-1 which may help replace hazardous ex-vivo WBC labeling procedures that are current clinical modality for imaging infection foci. 


\section{DISCLAIMER}

This report was prepared as an account of work sponsored by an agency of the United States Government. Neither the United States Government nor any agency thereof, nor any of their employees, make any warranty, express or implied, or assumes any legal liability or responsibility for the accuracy, completeness, or usefulness of any information, apparatus, product, or process disciosed, or represents that its use would not infringe privately owned rights. Reference herein to any specific commercial product, process, or service by trade name, trademark, manufacturer, or otherwise does not necessarily constitute or imply its endorsement, recommendation, or favoring by the United States Government or any agency thereof. The views and opinions of authors expressed herein do not necessarily state or reflect those of the United States Government or any agency thereof. 


\section{DISCLAIMER}

Portions of this document may be illegible in electronic image products. Images are produced from the best available original document. 


\section{Significant Accomplishments:}

A series of peptides related to cell adhesion molecules (CAM) and an immunomodulatory peptide were investigated for their efficacy as potential radiodiagnostic agents for thrombus, acute renal failure, and infection/inflammation imaging. In particular, peptides related to RGD peptide sequence, laminin peptide fragment YIGSR, and immunomodulating peptide tuftsin analog were studied.

The peptides were designed using two basic approaches. The first approach was a classical approach in which multiple copies of the bioactive sequence were grouped together either linearly or in a star peptide format so as to increase its binding affinity. The peptides in this configuration contained a chelator site to facilitate binding of ${ }^{99 \mathrm{~m}} \mathrm{Tc}$. Various peptide investigated according to this approach included, RGD and YIGSR based constructs. Both the YIGSR and RGD peptides synthesized according to this approach resulted in stable complexes with ${ }^{99 m} \mathrm{Tc}$. However, metabolically these complexes were not very stable, apparently because of protease action. This include both linear and YIGSR-star peptides in 2,4 and 8 configurations.

The second approach for peptide design was a newly developed rational computer assisted drug design (CADD) approach termed MIDAS (Metal ion Induced Distinctive Array of Structures). In this approach, the biological function domain and the ${ }^{99 m} \mathrm{Tc}$ complexing domain are fused together so that structurally these domains are indistinguishable. This approach allows construction of conformationally rigid metallo-peptide molecules (similar to cyclic peptides) that are metabolically stable in-vivo. Also because of rigid topography of the biological function domain in these molecules, the biological activity is 2-3 orders of magnitude higher than the native linear peptides. Additionally, this approach gives essentially carrier-free preparations since only the fraction of molecules complexed to ${ }^{99 m} \mathrm{Tc}$ are biologically active. The fraction of peptide molecules that remain unbound to ${ }^{99 \mathrm{~m}} \mathrm{Tc}$ are biologically inert and do not bind to receptors sites. All the newly designed peptides were screened in various in-vitro receptor binding and functional assays to identify a lead compound. The lead compounds were formulated in a one-step ${ }^{99 \mathrm{~m}} \mathrm{Tc}$ labeling kit form which were supplied to BNL for detailed in-vivo imaging in animals models of thrombus, acute renal failure and infection/inflammation. Two main peptide systems investigated according to MIDAS approach were RGD peptide and an immunomodulatory peptide called tuftsin.

\section{RGD Peptides for Imaging of Ischemic Renal Failure:}

RGD is a sequence related to CAM. It was shown earlier that the adhesive amino acid sequence ARG-GLY-ASP is of importance in the cell-to-cell and basal anchoring of renal tubular epithelium. As a result of ische nic injury the tubular epithelium looses its anchoring and $b$ comes exfoliated because ischemia causes "re-orientation" of receptor binding sites from base-lateral to apical. This re-orientation of binding sites leads to "promiscuous" cell-to-cell binding forming tubular plugs, increased tubular pressure and clinical evidence of oliguric renal failure. Pretreatment with RGD c2. Arcrease the ischemic injury effect and even completely blect it. We have studied the blood clearance of ${ }^{99 \mathrm{~m}} \mathrm{Tc}-\mathrm{RGD}$ in several species using normal control animals and animals with 60 and 120 min. clamping of renal artery (after contra-lateral nephrectomv), 
showing that during ischemic injury blood disappearance remains normal because of re-routing of excretion to the GI tract. Scintigraphic and autoradiographic microimaging revealed the differences between normal and ischemic kidneys compared to ${ }^{99 \mathrm{~m}} \mathrm{Tc}-\mathrm{DTPA}$, a measure of golemrular filtration rate, and to ${ }^{99 m} \mathrm{Tc}-\mathrm{MAG} 3$, a tripeptide compound used routinely for renal scintigraphy, namely increased binding to cortex of kidneys exposed to $45 \mathrm{~min}$. ischemic injury.

\section{YIGSR and RGD Peptides for Imaging of Thrombus:}

The YIGSR peptides were tested for their ability to image experimentally induced clots in dogs. In-vitro experiments with one of the peptides, YIGSR-II, showed high binding specificity to clots. The affinity for binding platelets showed marked species specificity. Highest binding affinity was seen for rat platelets, followed in this order by rabbit, human and dog platelets. Imaging experimentally induced thrombi in dogs (thrombogenic coil) was also investigated with ${ }^{99 m}$ Tc-YIGSR-II. Good imaged with clot to background ratios of 2:1 were obtained with very rapid blood clearance of the radiolabeled pe idide probably due to its metabolic degradation. These results indicated that YIGSR-II could be used as a prototype candidate for development of metabolically more stable agents that are also more specific for human platelet binding and for in-vivo clot imaging.

${ }^{99 m}$ Tc-RGD-II, a peptide designed according to MIDAS approach was metabolically stable agent that localized in the experimentally induced thrombus. It, however, also had a very rapid blood clearance which together with its low platelet affinity did not give high uptake in thrombus. Design of peptide species with higher affinity is needed to give better imaging results. At this time a series of such peptides are screened for their efficacy using in-vitro assays, particularly inhibition of $\mathrm{ADP}$-induced platelet aggregation. The $\mathrm{IC}_{50}$ of present compound range 1-100 $\mu \mathrm{M}$. A suitable lead candidate would preferably have $1 \mathrm{nM}$ activity.

\section{A New Approach to Infection Imaging Using a Tuftsin-mimetic Synthetic Leukotactic Peptide}

Tuftsin, a naturally occurring amino acid sequence, has been shown to have diverse action including the promotion of phagocytosis by PMN and macrophages, and enhances migration to infection sites. These immune modulatory effects of native tuftsin are short lived because tuftsin is quickly digested by proteases. Some of the digested segments bind and block receptors becoming antagonists to further action of tuftsin.

An approach intended to decrease the proteolytic vulnerability of tuftsin vas addressed by synthesis of analogs $x$ hich have different amino acid sequence, yet preserve the $g$ ometry needed for receptor binding. The metalloprotein compound formed after labeling with ${ }^{99 m} \mathrm{Tc}$ was found to have similar binding and overall biological properties similar to tuftsin with recentor affinity 100 times that of the criginal compound.

A series of metallo-peptide constructs related to tuftsin tetrapeptide have been designed and synthesized. All these peptides share a common designing principle that is the metal ion 
(99m Tc) is integral part of the molecule as far as biological activity is concerned. The molecule is biologically inactive prior to ${ }^{99 \mathrm{~m}} \mathrm{Tc}$ complexation. Apparently, the metal ion complexation induces a distinct conformational restriction in the molecule's geometrical conformation which is biologically advantageous. Since the design of compounds is by computer assisted rational design approach, the amino acid sequence of molecule differs from the native compound. For this reason in-vitro assays had to be performed to assess biological activity of these new compounds. A phagocytosis assay indicated preservation of function of these molecules ( $1-5 \mathrm{nM}$ concentration range). In addition, few analogs were found to be potent agonists while others were potent antagonists. Among the potent agonists were: ${ }^{99 \mathrm{~m}} \mathrm{Tc}-\mathrm{RMT}-1,{ }^{99 \mathrm{~m}} \mathrm{Tc}-\mathrm{PL}-642,{ }^{99 \mathrm{~m}} \mathrm{Tc}-\mathrm{PL}-703$, and among antagonists ${ }^{99 m} \mathrm{Tc}-\mathrm{RM}-505$ and ${ }^{99 \mathrm{~m}} \mathrm{Tc}-\mathrm{RM}-625$. All these peptides were studied for their localization at infection/inflammation foci in rodents. Localization ratios as high as (target to background) 4:1 (30 $\mathrm{min}$.), and 10:1 (120 min) were obtained with RMT-1. Imaging could be performed as early as $15 \mathrm{~min}$ and up to 6 hours. Based on these results, ${ }^{99 \mathrm{~m}} \mathrm{Tc}$-RMT-1 was selected for further animal experimentation in rabbits and dogs in infection/inflammation and osteomyelitis models.

We have demons vated that ${ }^{99 \mathrm{~m}} \mathrm{Tc}$-RMT-1, the synthetic analog of tuftsin has properties of an almost ideal agent for infection localization by scintigraphy. Soft tissue chemical and bacterial abscesses could be imaged $20 \mathrm{~min}$. after injection. Moreover bone infection, osteomyelitis, could also be rapidly localized. As opposed to currently used bone scanning with diphosphonate agents the distinction between bone remodeling due to non-infectious causes (fractures, arthritis, internal prosthetic devices), is easily made with ${ }^{99 m}$ Tc-RMT-1 scintigraphy.

The first steps towards obtaining an IND for human trials have been made and will be followed through.

A large batch of RMT-1 was also produced under GMP for initiating detailed clinical evaluations. A one-step labeling kit formulation was also produced and subjected to a six month stability study. The peptide kits were found to be stable during this time frame to give consistently good radiolabeling profile ( $90-95 \%$ radiochemical purity) and infection foci localization in mice.

The infection/inflammation imaging project is now being evaluated for a corporate collaboration for using a number of metallo-peptides for clinical evaluations.

\section{Problems Encountered:}

Peptides synthesized according to classical approach $v$ ere metabolically unstable. This group include peptides such as RGD-I, YIGSR-I, YIGSR-II, YIGSR-III, YIGSR-2-Star, YIGSR-4-Star, and YIGSR-8-Star. In the star peptide series 2-Star was most unstable than 4ani 8-Star peptides. The metabolic instability was reflected ac too fast blood clearance and unsatisfactory clot visualization. This problem was $\mathrm{Sc}^{\text {rad }}$ by using the alternate MIDAS approach of peptide design in which metal ion $\left({ }^{99 \mathrm{~m}} \mathrm{Tc}\right.$ ) forms integral structural part of the binactive molecule. 


\section{Industry Benefits Realized: Intermediate Technical Milestones:}

The development of peptide based drugs is severely restricted because of their inherent metabolic instability. MIDAS technology is a big step forward in this direction in that it affords metabolically stable molecules by tying up the peptide bonds with the metal ion rendering them uncleavable.

MIDAS technology also affords the synthesis of carrier-free radiolabeled preparations in a pure biological sense. Since the radiometal ion is required to hold the molecule in bioactive conformation, the fraction of molecules that get labeled with the radiometal ion are biologically active. Metal uncomplexed molecules remain biologically inert and do not block the receptors like digested tuftsin fragments do. This allows use of labeled kit without separating labeled material from the unlabeled species.

MIDAs technology also allows the substitution of one metal ion wish another to obtain biologically carrier-free metabolically stable species for radiotherapy. For example ${ }^{99 \mathrm{~m}} \mathrm{Tc}$ can be substituted with ${ }^{186} \operatorname{Re}$ or ${ }^{188} \operatorname{Re}$ to obtain a radiotherapeutic agent with similar biological characteristics.

Another advantage of this technology is use of smaller amount of precursor peptide to formulate a kit. The metal ion binding domain is structurally optimized to accept radiometal ion with high affinity. As such small amounts of peptide are sufficient to cause high specific activity preparations. For example $5 \mu \mathrm{g}$ of RMT-1 is sufficient to bind $80 \mathrm{mCi}$ or even higher of ${ }^{99 \mathrm{~m} T c}$. This could be of great advantage in situations where excess of unlabeled pharmacological agent might be causing undesirable side effects, e.g., neutropenia associated with chemotactic peptides.

\section{Laboratory Benefits Realized:}

The development of infection imaging agent based on MIDAS technology is a major accomplishment of this project. The MIDAS technology has wider applications that span outside radiopharmaceutical field in the development of non-radioactive therapeutics using stable metal ions. However, co.nmon and parallel development of non-radioactive and rad opharmaceuticals is a hallmark of this approach. In fact, use of identical radioactive and non-radioactive species is being considered as a great advantage in drug esearch and development. The radioactive versions of the compounds enable study of metabo'ism and kinetics including autoradiography and scintigraphy. 


\section{Recommended Follow-on Work:}

Infection/inflammation imaging using one of the newly developed metallopeptide tuftsin analogs warrant a pilot human clinical trial. High affinity, metabolic stability, radiochemical stability and purity, and low manufacturing costs are some of the very important attributes of this class of compounds. This product would be highly welcomed by the clinical community as a nonhazardous, safe, fast and less expensive alternative to ${ }^{111} \mathrm{In}$-WBC imaging protocols.

Development of RGD based clot imaging agent based on the elands provided by this work should give a peptide of desired platelet affinity. The peptides developed so far are metabolically and radiochemically stable, but have lower platelet affinity. There is a great demand by the clinical community for a clot imaging agent for deep vein thrombus (DVT) and in particular pulmonary emboli (PE).

\section{Potential Benefits from Pursuing Follow-on Work.}

A peptide based infection imaging agent will allow faster (minutes to few hours) imaging of the foci of infection/inflammation as compared to present modality of ${ }^{~} 11 \mathrm{In}$-WBC ( $\left.24 \mathrm{hrs}\right)$. In addition, the peptide based technique would also be non-hazardous and eliminate the need of ex-vivo WBC labeling and handling blood from HIV infected patients, as done now. Additionally, the peptide based procedure may help bring down the cost significantly. These two factor together may help increase the wider use of this procedure as compared to ${ }^{111} \mathrm{In}$-WBC scans currently being performed.

Development of a peptide based imaging agent for PE would be an essential tool in emergency rooms in hospital to make quicker diagnosis as compared to current practice of admitting patients for watch.

\section{Publications}

1. Wang G-J, Oster ZH, Som P, Pollack W, Yousef K, Zamora PO and Rhodes BA: A Tc-99m labeled laminin derived peptide, Tc-99m YIGSR for thrombus specific imaging. J. Nucl. Med. 35:106P, 1994.

2. Oster ZH, Som P, Noiri E, Wang G-J, Rhodes BA and Goligorsky MS: RGD containing neptide in experimental acute tubular necrosis (ATN) Autoradiographic microimaging studies. Third U.S. Soc. Wholebody Autoradiograph Meeting, Louisville, KY, 1994.

3. Oster ZH, Som P, Noiri E, Wang G-J, Cabahug CJ, Sharma S, Rhodes BA and Goligorsky MS: ${ }^{99 m}$ Tc-RGD peptide - a potential new agent for imaging accite tubular crosis (ATN). 9th Europ. Conf. Radiol. Europ. Radiol. 5:\%12, 1995.

4. Oster ZH, Som P, Noiri E, Wang G-J, Cabahug CJ, Sharma S, Rhodes BA and 
Goligorsky MS: ${ }^{99 m}$ Tc-RGD peptide (RGD) for imaging ischemic acute renal failure (ARF). J. Nucl. Med. 36:45P, 1995.

5. Noiri E, Som P, Oster ZH, Rhodes BA, Wang G-J, Cabahug C and Goligorsky MS: Technetium-labeled Arg-Gly-Asp (99mTc-RGD) As diagnostic tool for tubular obstruction in acute renal failure (ARF). XIIIth Int. Cong. Nephrology. Madrid, p. 166, 1995.

6. Goligorsky MS, Noiri E, Forest T, Miller F, Som P and Oster ZH: Integrins in acute renal failure (ARF). XIII Int. Cong. Neprology. Madrid., p 48, 1995.

7. Noiri E, Romanov V, Forest T, Gailit J, DiBona G, Miller F, Som P, Oster ZH and Goligorsky MS: Pathophysiology of renal tubular obstruction: Therapeutic role of synthetic RGD peptides in acute renal failure. Kidney Int. 48:1375-1385, 1995.

8. Noiri E, Forest T, Miller F, Sum P, Oster ZH and Goligorsky MS: Effects of RGD peptides on the course of acute renal failure: Clinical and diagnostic applicability. In: Acute Renal Failure: Emerging New Concept and Therapeutic Strategies, Eds. MS Goligorsky (Series Ed. J. Stein) Churchill Livingston, Inc., New York, pp. 379-399, 1995.

9. Noiri E, Romanov V, Czerwinski G, Gailit J, DiBona GF, Som P, Oster ZH and Goligorsky MS: Adhesion molecules and tubular obstruction in acute renal failure. Renal Failure 18:513-515, 1996.

10. Noiri E, Goligorsky MS, Wang G-J, Wang J, Cabahug C, Sharma S, Rhodes BA and Som P: Biodistribution and clearance of ${ }^{99 \mathrm{~m}}$ Tc-labeled Arg-Gly-Asp (RGD) peptide in rats with ischemic acute renal failure. J. Am. Soc. Nephrology 7:2682$2688,1996$.

11. Som P, Oster ZH, Sharma S, Wang J, Strotman NA and Rhodes BA: A novel approach to infection imaging using a synthetic ${ }^{99 \mathrm{~m}}$ Tc-labeled leukotactic peptide. J. Nucl. Med. 37:24P, 1996.

12. Som P, Oster ZH, Sharma S, Mar $\mathrm{k} M$ and Rhodes BA: Tc-99m-peptide, an analog of tuftsin, rapidly images abscess in laboratory animals. Ann. Nucl. Med. 10:S178, 1996.

13. Som I, Oster $\mathrm{ZH}$, Sharma $\mathrm{S}$, Wang J, and Rhodes BA: Diagnosis if osteomyelitis and soft tissue infection using ${ }^{99 m}$ Tc-labeled tuftsin-analog peptide. J. Nucl. Med. 38:132P 1997.

14. Sm P, Oster ZH, Sharma S, Wang J, Strotman NA and R'. 2 BA: Infection imaging with a new synthetic ${ }^{99 m}$ Tc-labeled leukotactic peptide. J. Nucl. Med. Submitted, 1997. 